\title{
Protecting environmental flows through enhanced water licensing and water markets
}

\author{
T. Erfani ${ }^{1,2, *}$, O. Binions ${ }^{2, *}$, and J. J. Harou ${ }^{1,2}$ \\ ${ }^{1}$ School of Mechanical, Aerospace and Civil Engineering, University of Manchester, Manchester, M13 9PL, UK \\ ${ }^{2}$ Department of Civil, Environmental and Geomatic Engineering, University College London, Chadwick Building, \\ Gower Street, London, WC1E 6BT, UK \\ *These authors contributed equally to this work.
}

Correspondence to: J. J. Harou (julien.harou@ manchester.ac.uk)

Received: 11 January 2014 - Published in Hydrol. Earth Syst. Sci. Discuss.: 12 March 2014

Revised: 28 November 2014 - Accepted: 5 December 2014 - Published: 3 February 2015

\begin{abstract}
To enable economically efficient future adaptation to water scarcity some countries are revising water management institutions such as water rights or licensing systems to more effectively protect ecosystems and their services. However, allocating more flow to the environment can mean less abstraction for economic production, or the inability to accommodate new entrants (diverters). Modern licensing arrangements should simultaneously enhance environmental flows and protect water abstractors who depend on water. Making new licensing regimes compatible with tradable water rights is an important component of water allocation reform. Regulated water markets can help decrease the societal cost of water scarcity whilst enforcing environmental and/or social protections. In this article we simulate water markets under a regime of fixed volumetric water abstraction licenses with fixed minimum flows or under a scalable water license regime (using water "shares") with dynamic environmental minimum flows. Shares allow adapting allocations to available water and dynamic environmental minimum flows vary as a function of ecological requirements. We investigate how a short-term spot market manifests within each licensing regime. We use a river-basin-scale hydroeconomic agent model that represents individual abstractors and can simulate a spot market under both licensing regimes. We apply this model to the Great Ouse River basin in eastern England with public water supply, agricultural, energy and industrial water-using agents. Results show the proposed shares with dynamic environmental flow licensing system protects river flows more effectively than the current static minimum flow requirements during a dry historical year, but that the total
\end{abstract}

opportunity cost to water abstractors of the environmental gains is a $10-15 \%$ loss in economic benefits.

\section{Introduction}

Recent projections show that the amount of available water runoff currently appropriated for human needs globally is around $50 \%$, and likely to rise to $70 \%$ by 2025 (Postel et al., 1996; Postel, 1998). Current water diversion practices lead to degradation of river environments in some areas, resulting in regional water scarcity and conflicts (Smakhtin et al., 2004).

Water trading developed in some countries as a response to water scarcity with the aim of allocating water efficiently (Bjornlund, 2003; Howe et al., 1986; Thobanl, 1997). In the US, Chile, South Africa and Australia trading is permitted or encouraged in some regions. In the US and Australia, government-allocated funds are used to buy back water allocations to leave water in the environment (Brewer et al., 2008; Wheeler et al., 2013; Wilkinson, 2008). These methods are short-term solutions to immediate water scarcity problems and such uses of public funds can be a contentious issue. Reforms of water allocation systems are under way in countries such as the United States, South Africa, Australia, Russia and England and Wales to ensure environmental protection in the longer term (Gleick et al., 2011; Stern, 2013; Young, 2012). In England there are significant institutional barriers to water trading (Environment Agency and Ofwat, 2008; Hodgson, 2006). 
The ability of water markets to help users adapt to water scarcity challenges is heavily dependent on the water resource management institutions (Grafton et al., 2011). The issues of fairness in water allocation between environmental and human uses, and between varying human uses have become controversial as economic considerations and market reallocation may not result in a socially just outcome (Syme et al., 1999). Without appropriate regulatory ability to preserve shared ecosystem services there is a risk that overabstraction will continue or worsen under market systems.

The objectives of water resource allocation systems are to regulate access to water resources, ensuring flexibility, security of access, predictability, and fairness, and to reflect public values and opportunity costs (Howe et al., 1986). More recently, environmental protection has been added to those goals. One of the methods used to preserve adequate river flows is to set a minimum flow below which water abstraction must reduce or cease (Acreman, 2005). These static threshold or minimum flow methods of maintaining river flows often do not achieve ecologically or economically efficient results (Arthington et al., 2006; Katz, 2011). The aquatic environment relies on a natural hydrological cycle, but human water abstractions alter the natural flow variability which is important to sustaining riverine species, and minimum flow regimes do not support natural flow regimes (Poff et al., 1997). Hence, fixed volumetric allowances have evolved into allowances with reference to river flow conditions such as "per cent of flow" regime, with abstractions limited to a sustainable share of the natural river flows (Richter et al., 2012). Environmental flow methods are used to determine the sustainable levels of abstractions. Over 200 environmental flow approaches have been developed to provide the policy-makers with tools to redesign water allocation systems ensuring that river ecology is protected, whilst taking into account human water needs (Acreman and Dunbar, 2004). Environmental flow methodologies have been developed and applied in 44 countries, spanning six world regions, with the US as the most active proponent of the approach (Tharme, 2003).

Allocation of water across individual water abstractors, similarly, should be linked to water availability. Examples of these new systems can be found in Australia (Libecap et al., 2010; Young, 2012), Chile and Mexico (Hodgson, 2006). Water allocations in this system are according to available water and river flow conditions. The shares are translated into volumetric licenses for each abstractor.

In redesigning a water allocation system policy makers need to assess how well the new system meets the objectives outlined above, and whether it promotes economically efficient allocation whilst preventing negative externalities of water diversions on the environment or other users. River basin modelling and integrated assessment (Loucks et al., 1981; Jakeman and Letcher, 2003) can provide insights into potential environmental and water allocation outcomes of the proposed changes. Hydroeconomic models that incorporate hydrology, institutions and economics are particularly relevant (Harou et al., 2009). Traditional hydroeconomic models can simulate aggregate regional results of water trading (Draper et al., 2003; Ward et al., 2006). To determine market outcomes at the scale of individual water diverters, however, it is important to simulate the transactions between individual water users. Cheng et al. (2009) developed a flow-path model formulation that allows tracking transactions between users. Erfani et al. (2013) presented an efficient variant used by Erfani et al. (2014) to model a surface water spot market.

This paper extends the generic water market simulation model proposed by Erfani et al. (2014) to assess possible outcomes of water trading under a share-based licensing system where allocations (water rights) are updated according to current flow conditions and dynamically updated environmental flows (Environment Agency, 2013; Young and McColl, 2005). The new model is applied to a case-study basin in eastern England. The performance of the proposed licensing system is compared to the currently used licensing system which uses static minimum environmental flows and volumetric licenses. The current system allocates fixed water volumes whilst the proposed system scales weekly licensed volumes proportionally to each abstractor's shares depending on flow conditions. The contribution of this paper is to represent a novel modern water management licensing system within a hydroeconomic water market simulator to assess the hydrological and economic impacts of the new policies on a real-world complex multi-sector water resource system.

The next section describes the generalised river basin model formulation used to model both licensing regimes. Section 3 outlines the case study and additional constraints to represent the Ouse Basin and its regulatory environment. Section 4 presents results followed by a discussion in Sect. 5 and conclusions in Sect. 6.

\section{Methods}

The model presented in this paper is an extension of the hydroeconomic model of Erfani et al. (2014) which uses economic optimisation to simulate and track pair-wise water market transactions between individual water users. This paper introduces dynamic environmental flows and scalable "share" licenses into the pair-wise transaction tracking hydroeconomic water market simulator to evaluate how they perform in a water trading context. The short-term spot water market considered here is a system where each user can observe the bid and ask prices of others, as could exist with an online transaction system. Model constraints are used to represent the physical, regulatory and water-user-specific realities to try and incorporate plausible trading behaviours. The model formulation described in Sect. 2.1 and Appendix B summarise previous work by Erfani et al. (2014). In this paper model extensions to model dynamic environmental 
flows and scalable water licenses are presented in Sects. 2.2 and 2.3.

\subsection{Pair-wise trading model}

The Erfani et al. (2014) model (see Appendix B for equations) uses economic optimisation subject to constraints to simulate a short-term (spot) market for water. The river network is modelled as a network of nodes (e.g. demands, storage reservoirs, junctions where flow links converge or diverge) and conveyance links (e.g. river "reaches", i.e. segments) and water balance is ensured at each junction or storage node (see e.g. Loucks et al., 1981; Loucks et al., 2005). Economic benefit functions that quantify the economic gains from water diverted must be provided for each demand node at each time step. The maximised objective function is the sum of economic benefits from water use across all users in each individual time step, the net of transaction costs. This objective function identifies trades that make economic sense whilst meeting constraints that ensure regulations are followed and plausible agent behaviours are considered. For example, it includes a penalty function for deviating from the target level of reservoir storage. Water-user nodes consume some water using their own license or by buying from other license holders, and can sell the rest to others. Since most abstractors' water use is not fully consumptive, some water is returned to the river as return flow. The sum of volumes of water abstracted and sold by the users cannot exceed both their annual and weekly licensed allocation.

\subsection{Dynamic environmental flows}

The total amount of water across all users allowed for abstraction is the difference between the natural flow (excluding human water diversions and additions) and the minimum flow (MinFlow) at the downstream gauges. MinFlow is used in the following equation:

$\sum_{\substack{i \\ \mathrm{CO}_{i l}=1}} x_{i l}^{k}+\operatorname{inFl}_{l} \geq$ MinFlow $_{j} \forall l \in$ Junction,

$j \in$ Gauge, $k \in$ river,

for both the fixed and dynamic environmental flow water management systems. $\mathrm{inFl}_{l}$ is the external inflow at junction node $l$. The junction node $l$ is connected to the gauge $j$ to record how much water passes by the gauge $j$. With fixed volumetric water abstraction licenses, water available for abstraction is set using a fixed value of minimum flows $\left(\right.$ MinFlow $_{j}$ ) regardless of the available flow recorded at the gauges. In the case of dynamic environmental flows, MinFlow $_{j}$ is a function of naturalised river flows (flow without human water abstractions). Naturalised river flows are estimated from the river flow through the gauging stations, and the MinFlow $j$ is the sustainable minimum level of river flows.

\subsection{License scaling}

Under license scaling, the river basin is divided into subcatchments separated by river flow gauging stations. The water available for abstraction at each gauge $j$ is divided between the upstream license holders in that subcatchment proportionally to their shares.

WaterAbstracted $_{i}^{k} \leq \begin{cases}\theta_{j} \times W k L i_{i}, & \mathrm{nFlGA}_{j}-\text { MinFlow }_{j} \leq \sum_{\substack{l \in \mathrm{User} \\ \mathrm{WlGA}_{l j}=1}} \mathrm{WkLi}_{l} \\ \mathrm{WkLi}_{i} & \text { otherwise }\end{cases}$
$\forall i \in$ User $k \in$ river,

where

$\theta_{j}=\frac{\operatorname{nFlGA}_{j}-\text { MinFlow }_{j}}{\sum_{\substack{l \in \mathrm{User} \\ \mathrm{WlGA}_{l j}=1}} \mathrm{WkLi}_{l}}$

In the above equation, $\mathrm{nFlGA}_{j}-$ MinFlow $_{j}$ is the water available for abstraction for license holders upstream of gauge $j$.

\section{Case study}

\subsection{Water management in England and Wales}

In England water diversions ("abstractions") are regulated by the Environment Agency (EA). The abstraction licenses incur yearly charges based on the volumetric size of the license, and not on the actual abstraction volumes. The licenses state maximum daily and yearly abstraction volumes. Environmental protection is enforced through license-specific handsoff flow (HoF) restrictions which refer to minimum flow required through the relevant gauging station, below which the license is temporarily suspended. There are emergency provisions set out in Sect. 57 of the Water Resources Act 1991 which reduce spray irrigation in times of drought. Water trading is allowed, but rarely carried out. There is no water license spot market; each transaction has to be assessed and approved by the EA over several months.

The current system was set up in the 1960s and is not designed to manage competing water uses effectively. HoFs were introduced in an attempt to protect the environment from overabstractions and were applied to newly issued licenses, with no change in allocations for legacy licenses. There is a lack of appropriate incentives or price signals for efficient water use and there are institutional barriers to water trading (Defra, 2011). The current licensing system in many areas results in overabstraction and environmental damage: $18 \%$ of river catchments are classed as overlicensed, and a further $15 \%$ as overabstracted (Environment Agency, 2008). In around a quarter of the water bodies in England and 7\% of the water bodies in Wales, new consumptive abstractions cannot be provided with reliable water supply (Environment 
Agency, 2011). Nationally, over a third of licenses are not utilised and kept as a reserve in case of a drought, making $20 \%$ of the licensed volume unused, but which could have otherwise been licensed to new uses requiring water (Environment Agency and Ofwat, 2012). Water trading could provide flexibility in regional water resource management and is being considered in individual water resource management zones (Acreman and Ferguson, 2010).

In response to the shortcomings of the current English abstraction licensing system, it is currently being reformed. The aim is to allow water abstractors to more easily manage changes in water availability and regulators to better guarantee environmental flows (Environment Agency and Ofwat, 2012). The new regime is due to be implemented by the mid- to late-2020s. In the meantime, the EA has been assessing sensitivity of rivers to abstractions through the Restoring Sustainable Abstraction program, and making changes to licenses on a case-by-case basis to help prevent further damage.

Water licensing changes in England and Wales are designed to comply with the European Water Framework Directive (WFD). The aim of the WFD is to bring the quality of rivers to "good ecological status". Methods to define environmental flow requirements have been developed to enable policy makers to move away from the "minimum flow" approach to a river management approach that takes into consideration human water needs (Acreman and Dunbar, 2004). These informed the environmental flow indicator (EFI) approach to dynamic environmental flows developed by the Environment Agency. The EFI approach uses flow duration curves to fix the percentage of flow that can be abstracted at different flow levels. Each river in England and Wales has been assigned with an "abstraction sensitivity band" according to its sensitivity to changes in flow. With reference to the abstraction sensitivity, the percentage of flow allowed for abstraction is assigned to each river (Environment Agency, 2013).

\subsection{Modelling the Great Ouse River basin}

To investigate the outcomes of potential license reform options, we apply the proposed model to the $3000 \mathrm{~km}^{2}$ Great Ouse River basin in eastern England (Fig. 1). The largest towns are Milton Keynes and Bedford. The basin is characterised by gently rolling land in the upper part and flood plains and meadows in the lower part. Average annual rainfall varies from $540 \mathrm{~mm}$ in the east to $670 \mathrm{~mm}$ in the west (Environment Agency, 2005).

There are 94 active surface water licenses belonging to users from four sectors: energy, agriculture, public and private water supply and industry. Approximate locations of users are shown in Fig. 1. Around $95 \%$ of yearly surface water abstractions are appropriated by the public water supply (PWS) company and either stored in the reservoir (marked PWS Reservoir in Fig. 1) or input into the treatment and dis-

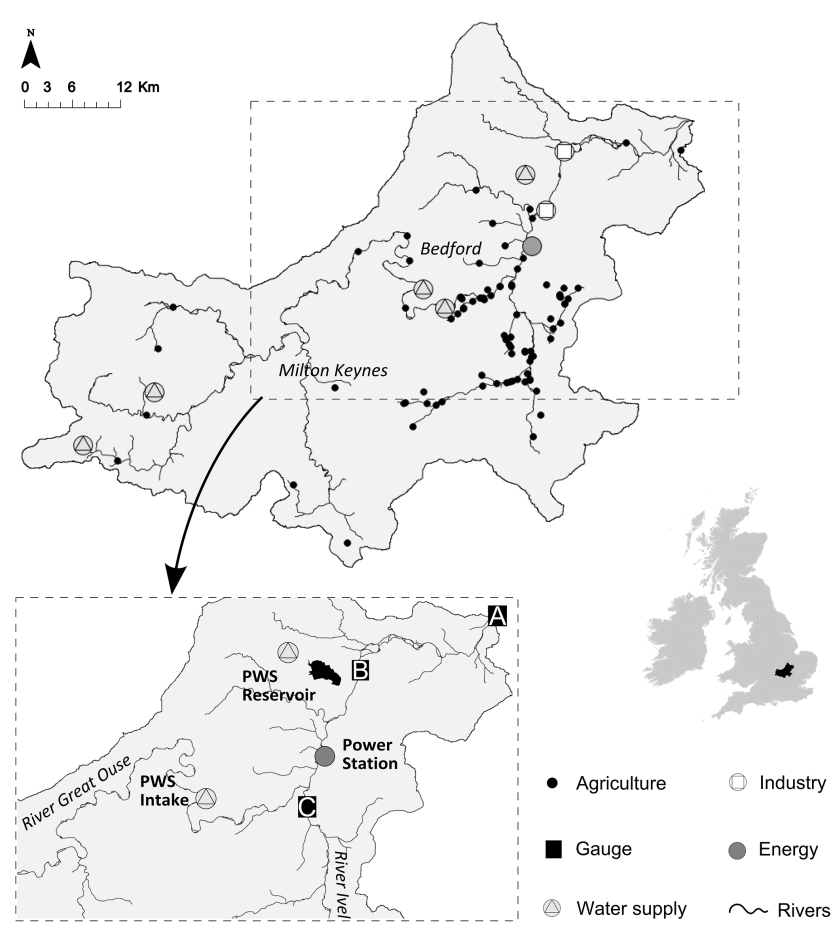

Figure 1. Map of the Great Ouse River basin showing approximate locations of water users and main river flow gauging stations: A last flow gauge in the basin (sink), B - Offord gauge defining license scaling for PWS reservoir and power station, $\mathrm{C}-$ gauge defining license scaling for agricultural users located in the River Ivel tributary.

tribution network (abstraction point labelled PWS Intake in Fig. 1). The second-largest water abstractor is the power station, which uses $4 \%$ of the total volume abstracted for cooling.

\subsection{Case-study-specific constraints}

In addition to the mass balance constraints described in Sect. 2, the constraints summarised below are used to represent regulatory rules and water-use behaviours in the basin. Incorporating rules is possible since the optimisation model is solved separately for each weekly time step; abstractors have limited hydrological foresight.

\subsubsection{Current license restrictions}

Water abstraction restrictions under the current system outlined in Sect. 3.1 are implemented to model the fixed volumetric water management system only. This is represented in the model by constraints on license usage. When the river flows are below the threshold limit defined by HoF, the license is temporarily suspended, prohibiting abstractions or trading of this license. The rule specified in Sect. 57 of the 1991 Water Resources Act reduces spray irrigation water diversions when river flow reaches low levels. In our model a 

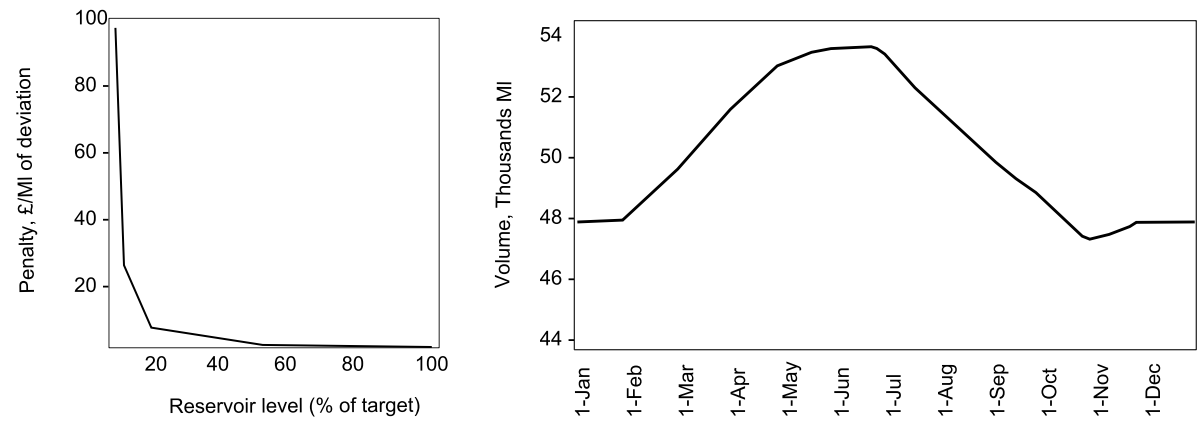

Figure 2. Reservoir storage deviation penalty (left panel), PWS reservoir storage targets (right panel).

$50 \%$ rationing is imposed on farmers when river flows are below the flow historically exceeded $95 \%$ of the time at the downstream gauges (see Appendix B for equations).

To model PWS reservoir operation rules, the following set of instructions is employed for both the fixed and dynamic water management licensing regimes. If reservoir storage is below the minimum volume, withdrawals from the reservoir stop. Storage target seeking behaviour by utilities is modelled by penalising storage target deviations in the objective function. As the reservoir levels get progressively lower, the more water-saving initiatives are implemented, and the lower proportion of the demand is satisfied, resulting in lower benefits from water use for the water company and the consumers. This loss of benefits is reflected in the reservoir deviation penalty factor $\alpha$ ( $y$ axis in Fig. 2, left panel):

Penalty $_{j}=\alpha\left|\operatorname{tRes}_{j}-\sum_{k \in \text { Owner }_{j}} \operatorname{Res}_{j}^{k}\right|$,

where tRes $_{j}$ is the seasonal storage target level (Fig. 2, right panel).

Water companies can implement demand reduction measures during droughts and temporarily restrict non-critical water uses to ensure that key water demands are satisfied. To reflect this in the model, the volume of water abstracted from the reservoir is reduced when storage levels are low using a hedging constraint (Appendix B).

When the PWS reservoir storage volume is low and demand reductions are implemented, the PWS intake license manager is not expected to sell any water. This leads to the following trading rule: when the reservoir level is $50 \%$ below target (half of target volume or less), water sales by PWS the following week are prohibited until the level recovers. Sensitivity analysis was carried out to test the impact on trading of more conservative policies where trading is stopped earlier (Sect. 4.4).

\subsubsection{Water trading}

Agricultural users require water for the irrigation season and will in many instances be unwilling to sell their license be- fore it. To represent varying degrees of water market participation, a limit on volumes sold by agricultural users was set in both the fixed and dynamic water management system modelling. For this a constraint (Appendix B) implicitly sets aside a portion of the yearly license for own use and ensures the user does not sell prematurely, exposing themselves to requiring water purchases later in the year. A "trade reluctance coefficient" is used to represent the degree to which farmers keep licensed water for their own use, and can be customised for each user enabling the analyst to consider diverse market participation. If the coefficient is set to 0 , the user always prefers to trade whenever it is economically beneficial, regardless of likely own future water needs. Conversely, users with a coefficient of 1 are conservative and will not sell water until they fully satisfy their yearly demand (at the end of the irrigation season).

\subsection{Parameterising dynamic environmental flows}

The model was applied to the Great Ouse River basin using hydrological data from one of the driest years on record, characterised by low river flows for the first 8 months of the year, followed by wet autumn and winter ("naturalised" flow in Fig. 3). Using the EFI method discussed in Sect. 2.3, and taking into consideration the abstraction sensitivity band of the river basin, the allowable water abstractions are calculated as proportions of naturalised flow (Table 1). In Table 1 , percentile of naturalised flow is the percentage of time that flow historically exceeded a given flow value provided by England's Environment Agency (Environment Agency, 2013). Please see Klaar et al. (2014) for further information on the EFI approach.

\section{Model results}

In the following we review model results focusing on how the two licensing systems diverge in protecting environmental flows, water allocated to each sector, and plausible trades under a short-term spot water market. 
Table 1. Allowable river diversions under the EFI system, defined as a percentage of river flow (source: Environment Agency, 2013).

\begin{tabular}{lcccc}
\hline Percentile of natural flow at downstream gauge of the subcatchment & $Q_{30}$ & $Q_{50}$ & $Q_{70}$ & $Q_{95}$ \\
\hline Percentage of naturalised flow allowed for abstraction (\%) & 26 & 24 & 20 & 15 \\
\hline
\end{tabular}

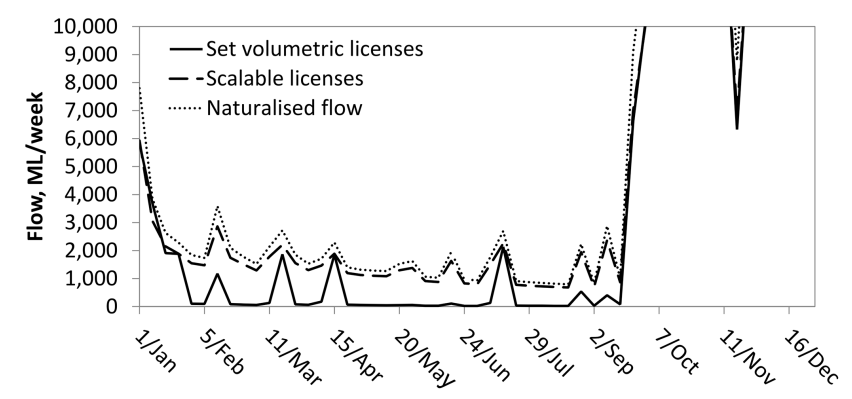

Figure 3. River flow at the last gauge in the basin (marked $\mathrm{A}$ in Fig. 1).

\subsection{Protection of the environment}

Figure 3 compares modelled river flow exiting the river basin under the two licensing systems. The current system leads to large variability in river flows through the year, decreasing to low levels incompatible with recent regulations such as the European Water Framework Directive (Acreman and Ferguson, 2010). This is the result of the asymmetric impact of environmental HoF conditions on individual licenses. HoFs were assigned to new licenses in the past to prevent overabstraction of rivers but were not applied retrospectively to early licenses granted in the 1960s (see Sect. 3.1). As a result, some (large) licenses are not affected by HoFs and the system is not effective at ensuring environmentally acceptable abstractions during the drought.

The drought river flows are improved with the proposed licensing system (Fig. 3) and its higher environmental allocation. Whereas the current licensing system brings the flow to nearly zero for over $40 \%$ of the dry year, the proposed licensing system never falls below $680 \mathrm{~mL}$ per week.

\subsection{Water diversions}

With the more stringent environmental protection enforced by the proposed scalable licensing system all users face a lower amount of water available for diversion. The total annual volume of water diverted decreases by over $40 \%$ (from 88000 to $50000 \mathrm{~mL}$ ). All water users except industry decrease their diversions: PWS reservoir by $44 \%$, PWS intake $-8 \%$, power station $-38 \%$, agriculture sector $-26 \%$, private water supply $-14 \%$. Industrial use increases its abstraction by less than $1 \%$.

The large decrease in the PWS reservoir abstraction is the main enabler of the higher river flows under the proposed system (Fig. 3). Under the current system there are no hands-
Table 2. Numbers of trades, buyers and sellers, and volumetric annual totals under the two licensing regimes for a simulated historical dry year (ML, millions of litres).

\begin{tabular}{lrr}
\hline & $\begin{array}{r}\text { Volumetric } \\
\text { licenses }\end{array}$ & $\begin{array}{r}\text { Sharing } \\
\text { system }\end{array}$ \\
\hline Number of trades & 299 & 678 \\
Sellers & 48 & 90 \\
Buyers & 19 & 32 \\
Total volumes traded, ML & 2750 & 4860 \\
\hline
\end{tabular}

off flow conditions imposed on the PWS licenses and the reservoir diverts heavily during the drought to stay within $50 \%$ of its storage targets (Fig. 4, top panel). Under license scaling, the reservoir's weekly water license is scaled down to less than a quarter of the reservoir's historical weekly diversion for most weeks of the year, causing a rapid decrease in reservoir storage volumes that almost empties the reservoir (Fig. 4, lower panel).

\subsection{License trading results}

Figures 5 and 6 show which sectors are buying and selling water under the current and proposed licensing systems respectively. Figure 5 shows that because of PWS's lack of HoF conditions, they are able to sell water to the energy sector throughout the year. Under the proposed system, as modelled (Fig. 6), where sectors are on equal footing, these rents are not available and PWS stops selling water at the end of April, at which point the energy sector begins buying from farmers (with higher transaction costs due to the larger number of transactions involved).

Lower diversion allowances under the proposed system lead to a more active water market, with the number of trades more than doubling ( $127 \%$ increase) and the volume traded increasing by $77 \%$ (see Table 2). Trading between users from different sectors also increases. Figure 7 shows the proportion of total yearly volumes transferred between sectors. Under the current licensing system the largest transactions by volume are from the PWS to the power station (94\%). Under the proposed shares-based system the power station is the largest buyer until autumn (Fig. 6), purchasing from both the PWS intake and agricultural businesses, and followed by transfers from the power station to the PWS reservoir in autumn and winter. Agricultural users also sell to the PWS reservoir towards the end of the year, after the growing season. The purchases by the PWS reservoir are made to refill 


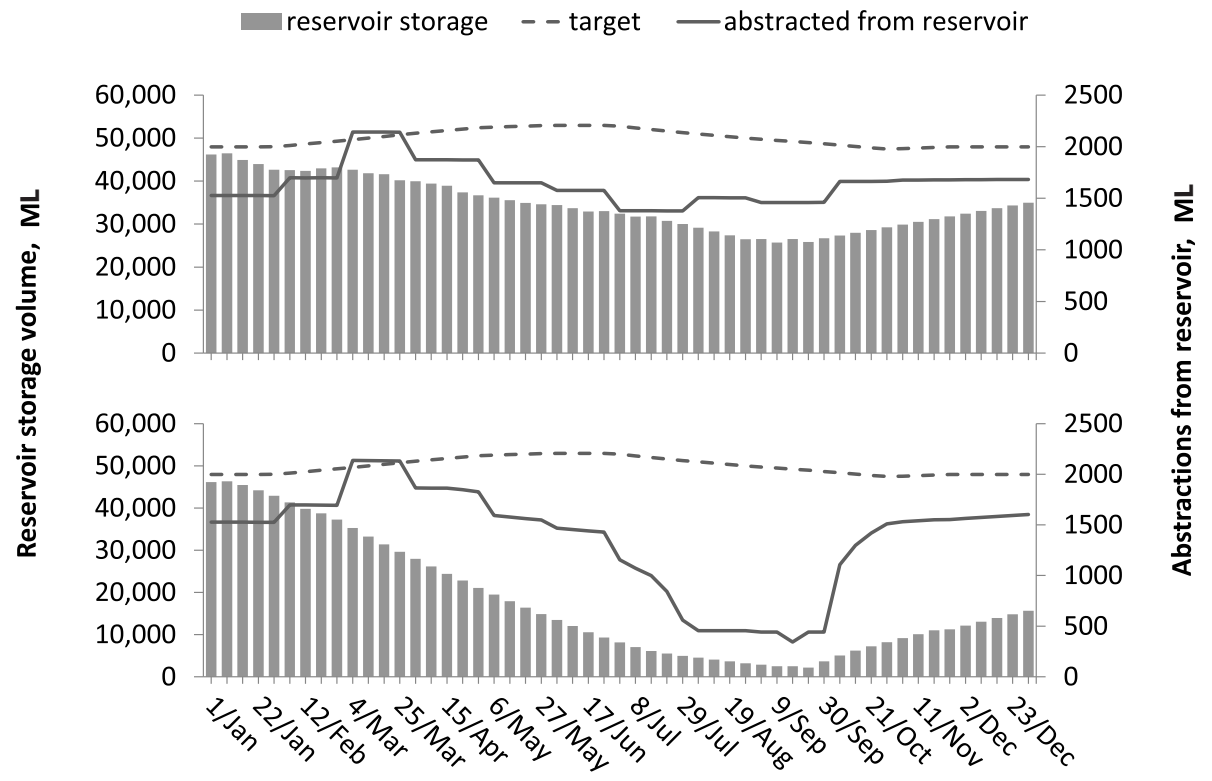

Figure 4. PWS reservoir storage and abstraction profiles for current (top panel) and proposed (bottom panel) licensing systems.
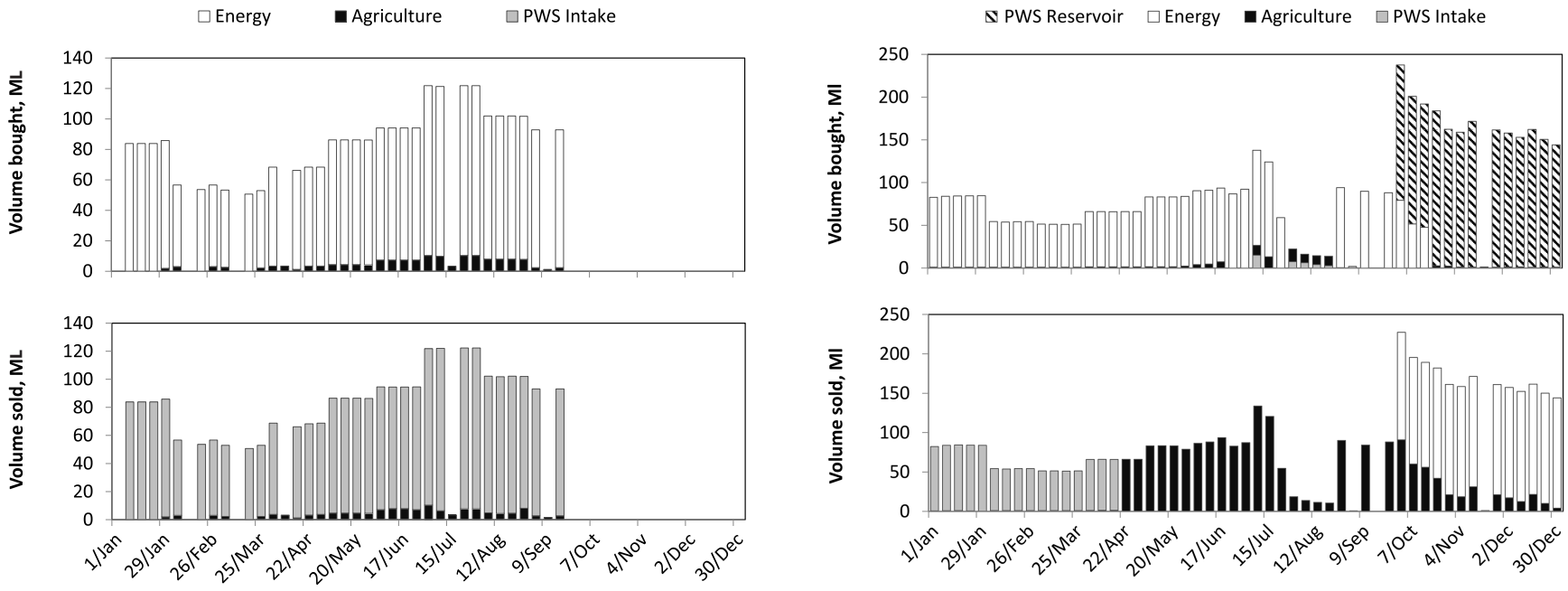

Figure 5. Water volumes bought (top panel) and sold (bottom panel) in millions of litres (ML) per week by sector under the current licensing (volumetric) system.

Figure 6. Water volumes bought (top panel) and sold (bottom panel) in millions of litres per week by sector under the proposed (scalable) licensing system.

the reservoir which was depleted through the year under the proposed licensing system.

In the current volumetric licensing simulation, license holders generally either sell or buy water throughout the year, and rarely switch from one status to the other. In the proposed shares-based system, however, some users who buy at the beginning of the year become sellers at the end of the year, and vice versa. Under the current system some license holders are affected by the drought more than others because of the stricter $\mathrm{HoF}$ conditions on their licenses, and are therefore systematically disadvantaged during droughts. With the pro- posed shares system, as simulated, all users are affected by reductions in the available resource, and short-term leasing enables them to manage their water needs effectively: selling in weeks when they have no or low demand for water and purchasing from other users when they have relatively high economic water demands unmet by their allocation.

Under proposed licensing, when the PWS reservoir storage volume reaches half of the target level by mid-April, PWS intake ceases selling water due to the trading constraint outlined in Sect. 3.3.2, PWS intake becomes a buyer in JulyAugust, purchasing small volumes from private water sup- 

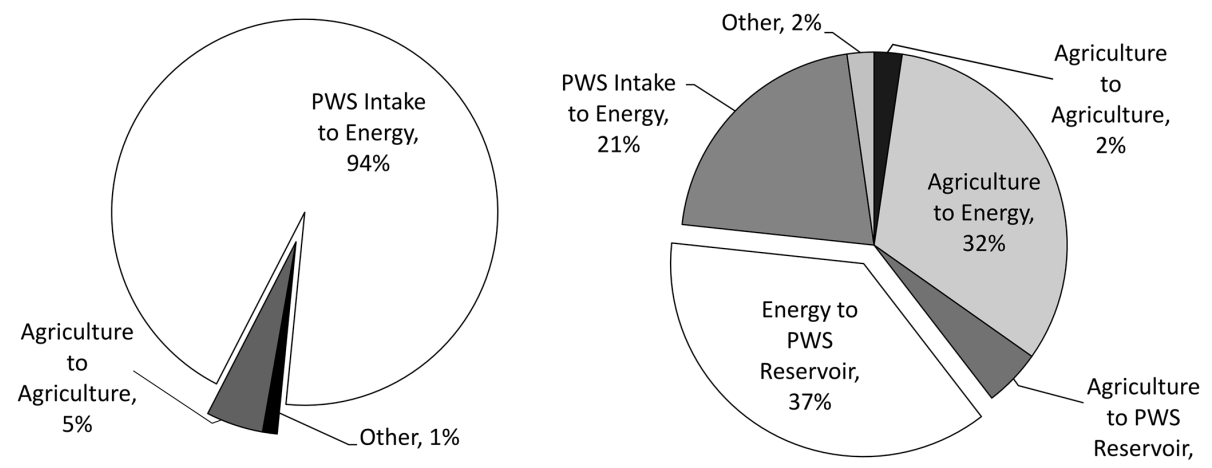

$5 \%$

Figure 7. Proportion of the total annual volume of trade transactions between sectors under the current (left panel) and proposed (right panel) licensing systems as simulated in a dry year.

ply license holders and farmers taking advantage of the first opportunity to start filling its reservoir. Under the current licensing system water trading stops as river flow recovers in mid-September, whereas in the shares-based system, trading continues until the end of the year. The reason for this is the large impact of license scaling on the PWS reservoir, as discussed in Sect. 4.2. Low storage volumes activate demand reduction measures which impose an opportunity cost on the water company and its customers and the marginal value of stored water increases (as represented by the penalty function defined in Sect. 3.3.2). The reservoir is refilled late in the year using its own license and purchases from other users.

\subsection{PWS trading rule sensitivity analysis}

PWS is the largest abstractor in the catchment, the largest single seller of water licences in the current system simulation, and the second-largest in the proposed system of scaled licences. A sensitivity analysis has been carried out to test the effect of the PWS trading rule outlined in Sect. 3.3.1 on model results. A more conservative attitude to trading is considered where the PWS intake stops selling water if storage is 30 or $10 \%$ below the storage target. The impact of these two scenarios on trades and sector benefits were assessed and compared to the original case where PWS stops trading if storage goes below $50 \%$ of the storage target.

Figure 8 shows changes in volumes sold, by sector, under the two licensing systems with stricter PWS trading rules. Under the current system, as the PWS intake reduces its yearly volumes sold, agriculture increases its sales. The volumes sold by agriculture with the $30 \%$ rule are 5 times the volume sold under the $50 \%$ rule. The number of sellers is increased from 48 to 69 with $30 \%$ below the storage target trading rule, and to 75 with $10 \%$ below the storage target trading rule. The overall total volumes sold per year reduce by around $50 \%$ as the trading rule is changed from 50 to $10 \%$ below the storage target.

Under the proposed system, the PWS intake is not the largest seller, and the reduction in its volumes sold does not

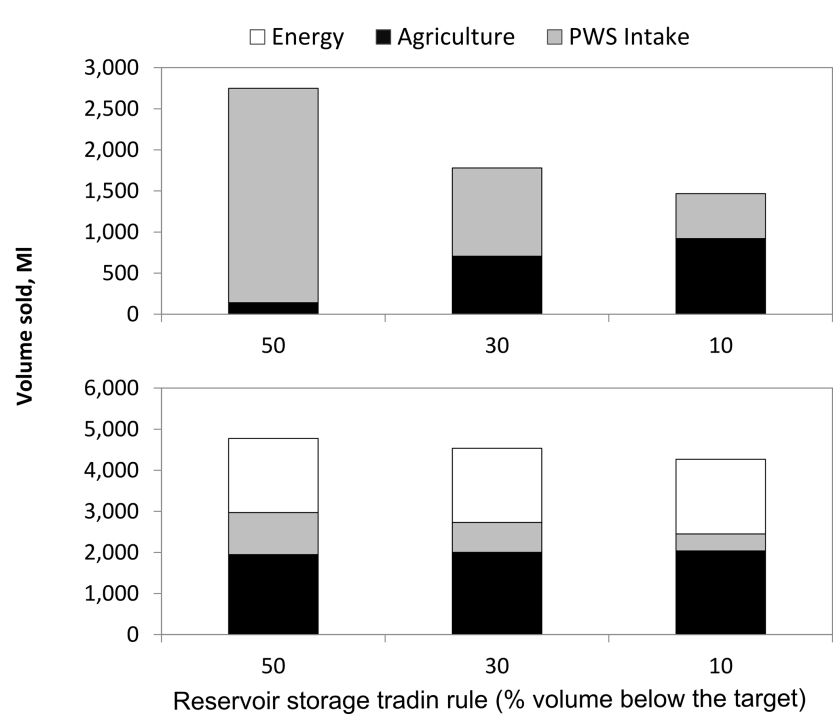

Figure 8. Effect of more conservative PWS trading rule on volumes sold under the current licensing system (top panel) and the proposed system (bottom panel). The water market under the proposed system is more active and less affected by the change in PWS trading policy.

produce as large of an effect on overall trading results. The number of sellers remains at 90 because all water users with water to sell are already participating in the market. The volumes sold by agriculture increase slightly (around 5\% increase as the rule changes from 50 to $10 \%$ below the storage target). The overall total volumes sold reduce by around $10 \%$.

The agriculture sector's and the power station's benefits from water use reduce as the PWS intake adopts a more conservative selling rule. Due to higher selling volumes by agriculture, its benefits from water use reduce by $25 \%$ (current system) and $23 \%$ (proposed system). The overall reduction in the volumes sold means a reduction in the power station's ability to supplement its allocated water volumes by buying 

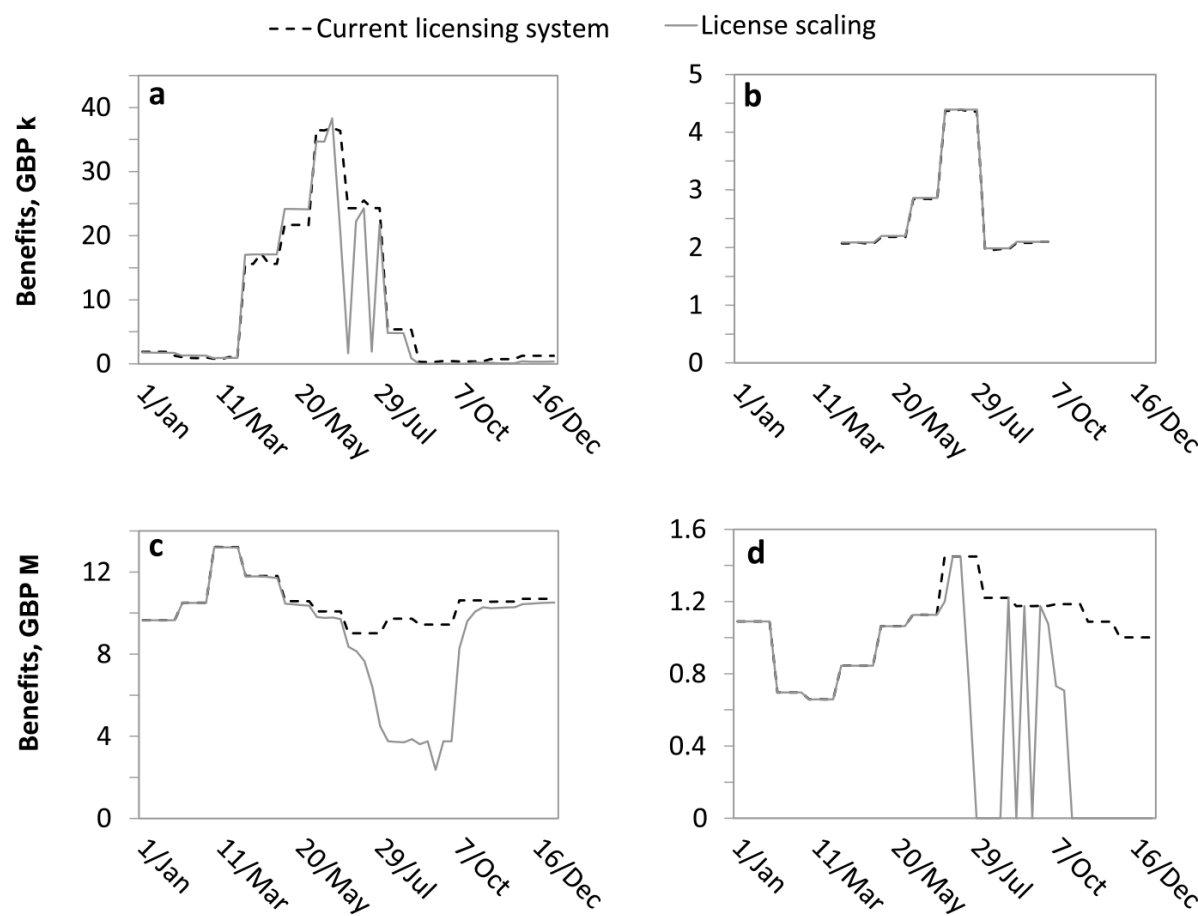

Figure 9. Comparison of gross economic benefits by sector from water use under the current and proposed licensing systems acting in conjunction with a short-term water market. The results are aggregated by sector: (a) agriculture; (b) industry; (c) water supply; (d) energy. The top panels show benefits in thousands of pounds and the bottom one in millions.

from other sectors, and its benefit reduces by $30 \%$ (current system) and $21 \%$ (proposed system).

These results suggest that the water market under the proposed licensing system can be less responsive to a single large user's attitudes to trading.

\section{Discussion}

The model tracks individual transactions allowing the analyst to assess how water markets could operate under different water licensing regimes and how individual abstractors could be affected. The aim of the model is to inform the policy makers of the potential outcomes of water management regulations and assess the effectiveness of a proposed licensing system in increasing environmental protection whilst reducing economic costs of water scarcity.

Gross economic benefits from water use are estimated for each abstraction license holder using their economic water demand functions (see Erfani et al. (2014) for details). For each week, the benefits generated from water use by each abstractor were aggregated into sectoral benefits. Figure $9 \mathrm{com}-$ pares the economic benefits by sector generated from water use for the two licensing systems in conjunction with the modelled water market. The energy sector sees the largest decrease in benefits due to the increased environmental protection of the proposed licensing system mostly due to the sector's inability to buy water from public water under drought.
The water company also incurs significant summer losses as it introduces restrictions. English policymakers are currently discussing the possible "grandfathering" of the current system priorities in the new licensing system; this would result in a multitiered scaling system where certain sectors have priority over others. As the details of such a system were not yet established, these have not been modelled, but if PWS were given priority within the scaled system, its loss of benefits would likely decrease.

Compared to the current licensing arrangement plus a market, the loss in benefits through the dry year across all sectors in our study case is estimated at GPB 94 million (a $15 \%$ reduction, from GBP 611 million for current licensing to GBP 517 million with the proposed system, both with the modelled surface water market). Erfani et al. (2014) estimated the total annual economic benefits for the same system and year with current licensing but without trading at GBP 575 million. In this case, the estimated opportunity cost of improved environmental flows is GBP 58 million, a $10 \%$ loss in economic benefits.

These opportunity costs for improving environmental flows may appear large. Our analysis uses catchment inflows from one of the driest years on record so this cost can be considered an upper bound on potential costs imposed on water users for enhanced environmental performance. Also, if the power station had an alternative supply to its surface water licence, its opportunity costs would decrease. To put 
the value in perspective, a survey by NERA (2007) estimated the present value of improvements in the water environment of all water bodies in the UK to be between GBP 18 and 29 billion (benefits incurred for an indefinite period), or between GBP 618 and 1020 million per year. Garrod and Willis (1996) estimated the annual value of alleviating low flows for the River Darent (river catchment area is $14 \%$ of the Great Ouse) at around GBP 37 million (GBP 2011).

Our model uses a single-objective ("aggregate") optimisation formulation that maximises the total social welfare of all water users to simulate the water market. Single-objective optimisation emulates centralised water allocation but is appropriate to model regulated water markets, "as long as interactions between agents and competition for resources can be interpreted in a competitive market paradigm" (Britz et al., 2013).

Several model limitations and simplifications should be mentioned. Groundwater resources were excluded from the model because we focus on the effects of changing the surface water licensing system. Abstraction license holders sometimes possess more than one license, sometimes for both surface water and groundwater abstractions. In this case, they will likely draw strategically from across their asset base (e.g. a water company will cost minimise when choosing sources), and such strategic abstraction would increase in a market - this is not considered in our current model where each abstraction point is modelled independently. Some abstractors, particularly agricultural ones, have small "winter storage" reservoirs to enable inter-temporal water management. Such users would likely switch between different water sources during droughts and involve reservoirs in sophisticated and diverse ways. At the time of the analysis, we did not have data on the locations and capacities of small reservoirs and so this detail is left to later work. Most strategic behaviours across different assets and over time (long-term decisions) are not reflected and are beyond the scope of this paper.

Economic water demands were estimated using data in the literature and are indicative of the water values across the different uses in our catchment. In our model, water diversions and trading are driven primarily by the spatially and temporally varying values of water as encoded in weekly demand curves for each abstractor. In reality, economic considerations are not the only drivers for human behaviour. Actual water markets would depend on the pre-existing social networks within the basin, preferences and attitudes towards trading, as well as perceptions of fairness and justice (Syme et al., 1999). Such motivations were not represented in our hydroeconomic model because they are not known. We take steps to represent some attitudes to trading by introducing a trade reluctance coefficient for agricultural users and embedding water company operating rules regarding their assets by a rule on trading. Furthermore, in our model the propensity of different agents to trade with each other can be calibrated on a pair-wise basis using transaction costs. In our applica- tion we set transaction costs by abstractor sector but a more detailed study of transaction costs could be performed.

\section{Conclusions}

This paper uses a hydroeconomic model to assess the performance of two water licensing regimes in conjunction with surface water markets. The first regime is the minimum-flowbased system with fixed volumetric licenses currently used in England and Wales. The second one is a proposed licensing system based on scalable licenses where shares are translated into actual permissible allocation volumes depending on minimum environmental flows that are set dynamically to adapt to naturalised flow conditions. The model was applied to the Great Ouse River basin in eastern England over a historically dry year.

Results suggest the proposed dynamic environmental flow with scalable licensing system is better able to prevent very low flows during droughts than the current abstraction regime based on volumetric licensing. Flows under the proposed system do not reduce below $680 \mathrm{~mL}$ per week, whereas under current licensing flows reduce down to nearly 0 for over 4 months of the year. With more water left to the environment, less water is available to satisfy human water demands, leading to a more active water market. The number of trades under the scalable licenses system is more than double the number under the current system and the volume traded is $77 \%$ greater. Also, the water market under the proposed system was less sensitive to a reduction in trading by one large agent (we tested this for PWS). Still the more active water market is not able to fully compensate for the loss of abstraction (increases in environmental flows); the opportunity cost of the increased environmental quality in the dry year is a loss of about $15 \%$ compared to the current licensing system with a water market, or $10 \%$ when compared to current system without a market (the current situation).

As pressure on water resources increases, water licensing systems will be expected to balance human and environmental water uses in increasingly effective and sophisticated ways. The English water allocation regime is currently being redesigned to protect environmental flows whilst minimising the societal economic cost of water scarcity. Water markets are viewed as part of the solution as they allow short-term economically efficient reallocation of water during scarcity events. In designing new water allocation institutions regulators will want to assess how new water allocation systems could work in conjunction with water trading to manage droughts. Customised hydroeconomic models, such as the one applied in this paper, help simulate coupled humanenvironmental systems, predict plausible behaviours and impacts, and assess proposed policies. 


\section{Appendix A: Nomenclature}

Table A1. Nomenclature.

\begin{tabular}{|c|c|}
\hline Junction & No-demand and non-storage nodes which join tow or more links in the network \\
\hline User & The set of all licensed river abstractors including agriculture, industry, water supply and energy \\
\hline Owner & The set of all water right holders, reservoirs and the river \\
\hline$x_{i j}^{k}$ & Decision variable, the water flowing from node $i$ to $j$ with license holder $k$ \\
\hline $\mathrm{inFl}_{i}$ & External hydrological inflow at junction node $i$ \\
\hline $\mathrm{CO}_{i j}$ & Connectivity matrix which contains 1 if node $i$ is connected to node $j, 0$ if no connection \\
\hline $\mathrm{pRes}_{j}^{k}$ & Reservoir $j$ storage carried over from previous time step with water license $k$ \\
\hline $\operatorname{Res}_{j}^{k}$ & Reservoir $j$ storage with water license $k$ \\
\hline $\operatorname{tRes}_{j}$ & Reservoir $j$ target \\
\hline WaterAbstracted ${ }_{i}^{k}$ & Water consumed by user $i$ which is either bought from owner $k$ or abstracted from river using user $i$ 's license \\
\hline Trade $_{i}^{k \in \text { river }}$ & Water license leased for one time step by user $i$ \\
\hline ReturnFlow $_{i j}$ & Water returned back to the river at downstream junction node $j$ of user $i$ based on the consumption factor of user $i$ \\
\hline $\mathrm{DW}_{i j}$ & Junction node $j$ downstream of user $i$ \\
\hline consFactor $_{i}$ & Fraction of water evaporated relative to diverted for user $i$ \\
\hline Discharge $_{j}$ & Discharge sink $j$ at the mouth of the river \\
\hline $\mathrm{WkLi}_{i}$ & Weekly license allowance for user $i$ to abstract water from river \\
\hline $\mathrm{YrLi}_{i}$ & Yearly license allowance for user $i$ to abstract water from river \\
\hline Deviation $_{j}$ & Deviation of reservoir $j$ from its target storage volume \\
\hline $\mathrm{flGA}_{j}$ & Flow at gauge $j$ \\
\hline $\mathrm{AlGA}_{j}$ & Allowable flow at gauge $j$ \\
\hline $\mathrm{RuGA}_{i j}$ & $\begin{array}{l}\text { Information with regards to the hands off flow condition which equals one if user } i \text { abstraction is controlled with } \\
\text { the level of flow at gauge } j\end{array}$ \\
\hline$Q_{95} \mathrm{GA}_{j}$ & $Q_{95}$ flow level at gauge $j$ \\
\hline $\mathrm{UpGA}_{i j}$ & Agriculture user $i$ upstream of gauge $j$ \\
\hline WaterUse ${ }_{i}^{t}$ & Water used by user $i$ at time $t$ including the abstraction and trading \\
\hline $\mathrm{sL}_{i}^{t} \quad{ }^{l}$ & Selling limit for user $i$ at time $t$ \\
\hline $\mathrm{EWN}_{i}$ & Historical expectation of water needs for user $i$ \\
\hline
\end{tabular}




\section{Appendix B: Formulation details}

In this appendix we reproduce the formulation from Erfani et al. (2014) for reader convenience. Section headers specify which section of the current paper the equation relates to.

\section{B1 Formulations for Sect. 2.1}

The pair-wise trading model follows the multi-commodity modelling framework with an extra index $k$ on the flow variable to represent water ownership (Erfani et al., 2013). The objective function of the model is

$$
\begin{aligned}
\text { NetBenefit } & =\sum_{i \in \text { User }_{\text {er }} \text { totalBenefit }_{i}} \\
& -\sum_{i \in \text { User }_{\text {totalCost }}}-\sum_{j \in \text { Reservoir }} \text { Penalty }_{j},
\end{aligned}
$$

subject to the following mass balance constraints:

$$
\sum_{\substack{j \\ \mathrm{CO}_{j i}=1}} x_{j i}^{k}+\mathrm{inFl}_{i}+\sum_{l \in \mathrm{User}} \operatorname{ReturnFlow}_{l i}=\sum_{\substack{j \\ \mathrm{CO}_{i j}=1}} x_{i j}^{k}
$$

$\forall i \in$ Junctionk $\in$ Owner, $\mathrm{DW}_{l i}=1$,

$$
\sum_{i} x_{i j}^{k}+\operatorname{pRes}_{j}^{k}=\operatorname{Res}_{j}^{k}+\sum_{\substack{i \\ \mathrm{CO}_{j i}=1}} x_{j i}^{k} \forall j \in
$$

Reservoirk $\in$ Owner,

$$
\sum_{\substack{j \\ \mathrm{CO}_{j i}=1}} x_{j i}^{k}=\sum_{\substack{j \\ \mathrm{CO}_{i j}=1}} x_{i j}^{k}+\text { WaterAbstracted }{ }_{i}^{k}+\text { Trade }_{i}^{k \in \text { river }}
$$

$\forall i \in$ Userk $\in$ Owner,

$$
\operatorname{Trade}_{i}^{k \in \text { river }}=\sum_{\substack{j \\ \mathrm{CO}_{i j}=1}} x_{i j}^{i}
$$

$\forall i \in$ User,

ReturnFlow $_{i j}=\sum_{k \in \text { Owner }}\left(1-\right.$ consFactor $\left._{i}\right)$ WaterAbstracted $_{i}^{k}$

$\forall i \in \mathrm{User} \mathrm{DW}_{i j}=1$,

$$
\sum_{k \in \text { river }} \sum_{\substack{i \\ \mathrm{CO}_{i j}=1}} x_{i j}^{k}=\text { Discharge }_{j}
$$

$\forall j \in$ Discharge.

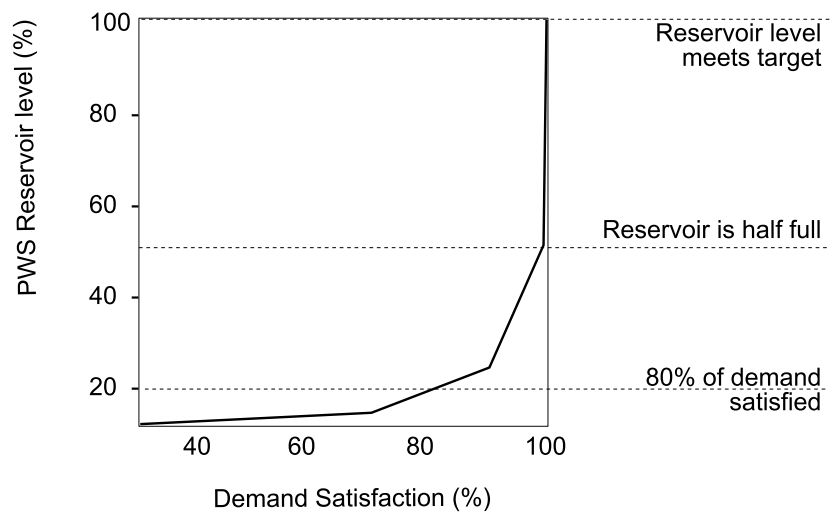

Figure B1. Public water supply company hedging rule.

\section{B2 Formulations for Sect. 3.3.1}

At the beginning of each week the river flow is checked and if the value is below the HoF limit, the license is suspended for the upcoming week (Erfani et al., 2014). This is imposed using the following constraint:

$\left(\mathrm{flGA}_{j} \leq \mathrm{AlGA}_{j}\right) \longrightarrow\left(\right.$ WaterAbstracted $\left._{i}^{k \in \text { river }}+\operatorname{Trade}_{i}^{k \in \text { river }}=0\right)$

$\forall i \in$ user, $j \in$ Gauge, RuGA $_{i j}=1$.

In addition, the $50 \%$ rationing is imposed on farmers using the following set of check constraints:

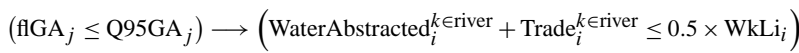

$\forall i \in$ Agriculture, $j \in$ Gauge.

For the PWS reservoir, the volumetric capacity constraint is as follows:

$2627 \leq \sum_{k \in \text { Owner }} \operatorname{Res}_{j}^{k} \leq 55450$,

$\forall j \in$ Reservoir.

The hedging constraint for water company demand reduction is represented by

WaterAbstracted $_{i}^{j}=F\left(\sum_{k \in \text { Owner }_{j}} \operatorname{Res}_{j}^{k}\right)$,

$\forall i \in \operatorname{user} j \in \operatorname{ReservoirCO}_{l i}=1$,

where $F($.$) is the function shown in Fig. B1 which represents$ the relationship between the reservoir level, as a percentage of the target, and the proportion of demand that is satisfied.

\section{B3 Formulations for Sect. 3.3.2}

At each weekly time period $t$ of the modelling, agricultural willingness to sell their license is represented using

Trade $_{i}^{k \in \text { river }} \leq \max 0, \mathrm{sL}_{i}^{t}$

$\forall i \in$ user, 
This limit (sL) applies until the farmer abstracts a proportion $c_{i}$ of their expected water needs $\left(\mathrm{EWN}_{i}\right)$ which is based on their historical yearly water use. For each user $i$,

$\mathrm{sL}_{i}^{t}= \begin{cases}\mathrm{sL}_{k}^{t-1}-\text { WaterUse }_{i}^{t}, & \begin{array}{l}\text { Sum of abstraction up to timet } \leq c_{i} \times \mathrm{EWN}_{i}, \\ \text { otherwise }\end{array} \\ \mathrm{WLLi}_{i}, & \end{cases}$ where WaterUse is the sum of water diverted and sold, $c_{i}$ is a value ranging from 0 to 1 , and

$\mathrm{sL}_{i}^{0}=\mathrm{YrLi}_{i}-c_{i} \times \mathrm{EWN}_{i}$.

(B21) 
Acknowledgements. This work was undertaken within the "Transforming Water Scarcity though Trade" (TWSTT) project funded by the UK Engineering and Physical Science Research Council (EPSRC grant EP/J005274/1). The research was partially funded by Anglian Water and DEFRA through the Cambridge Programme for Sustainability Leadership (CPSL) and by the "Valuing Water" RG07 project funded by UK Water Industry Research (UKWIR). Hydrological data and software assistance was provided by John F. Raffensberger, Ralph Ledbetter and George A. F. Woolhouse. We thank them and other colleagues who contributed to this work including Jean Spencer, Martin Silcock, Henry Leveson-Gower, Keith Weatherhead, Mike Young, Darren Lumbroso, Steven Wade, and others. An anonymous reviewer provided comments that improved the paper. All errors or omissions are the authors' alone.

Edited by: A. Guadagnini

\section{References}

Acreman, M.: Linking science and decision-making: features and experience from environmental river flow setting, Environ. Modell. Softw., 20, 99-109, doi:10.1016/j.envsoft.2003.08.019, 2005.

Acreman, M. C. and Dunbar, M. J.: Defining environmental river flow requirements - a review, Hydrol. Earth Syst. Sci., 8, 861876, doi:10.5194/hess-8-861-2004, 2004.

Acreman, M. C. and Ferguson, A. J. D.: Environmental flows and the European Water Framework Directive, Freshwater Biol., 55, 32-48, doi:10.1111/j.1365-2427.2009.02181.x, 2010.

Arthington, A. H., Bunn, S. E., Poff, N. L., and Naiman, R. J.: The challenge of providing environmental flow rules to sustain river ecosystems, Ecol. Appl., 16, 1311-1318, 2006.

Bjornlund, H.: Efficient water market mechanism to cope with water scarcity, Int. J. Water Resour. Develop., 19, 553-567, 2003.

Brewer, J., Glennon, R., Ker, A., and Libecap, G.: 2006 Presidential Address Water Markets in the West: Prices, Trading, and Contractual Forms, Econ. Inquiry, 46, 91-112, 2008.

Britz, W., Ferris, M., and Kuhn, A.: Modeling water allocating institutions based on Multiple Optimization Problems with Equilibrium Constraints, Environ. Modell. Softw., 46, 196-207, doi:10.1016/j.envsoft.2013.03.010, 2013.

Cheng, W.-C., Hsu, N.-S., Cheng, W.-M., and Yeh, W. W. G.: A flow path model for regional water distribution optimization, Water Resour. Res., 45, W09411, doi:10.1029/2009WR007826, 2009.

Defra: Water for life, TSO, Norwich, UK, 2011.

Draper, A., Jenkins, M., Kirby, K., Lund, J., and Howitt, R.: Economic-Engineering Optimization for California Water Management, J. Water Resour. Pl. Manage., 129, 155-164, doi:10.1061/(ASCE)0733-9496(2003)129:3(155), 2003.

Environment Agency: The Upper Ouse and Bedford Ouse Catchment Abstraction Management Strategy, Environment Agency, Bristol, UK, March 2005.

Environment Agency: Water resources in England and Wales - current state and future pressures, Environment Agency, Bristol, UK, December 2008.

Environment Agency: The case for change - current and future water availability, Bristol, UK, 2011.
Environment Agency: Environmental Flow Indicator, edited by: Environment Agency, Bristol, UK, 2013.

Environment Agency and Ofwat: Review of barriers to water rights trading, London, UK, 2008.

Environment Agency and Ofwat: The case for change: Reforming water abstraction management in England, Environment Agency, Bristol, UK, 2012.

Erfani, T., Huskova, I., and Harou, J. J. Tracking trade transactions in water resource systems: A node-arc optimization formulation, Water Resour. Res., 49, 3038-3043, doi:10.1002/wrcr.20211, 2013.

Erfani, T., Binions, O., and Harou, J. J., Simulating water markets with transaction costs, Water Resour. Res., 50, 4726-4745, doi:10.1002/2013WR014493, 2014.

Garrod, G. D. and Willis, K. G.: Estimating the Benefits of Environmental Enhancement: A Case Study of the River Darent, J. Environ. Pl. Manage., 39, 189-203, 1996.

Gleick, P., Allen, L., Christian-Smith, J., Cohen, M. J., Cooley, H. R., Heberger, M., Morrison, J., Palaniappan, M., and Schulte, P.: The World's Water, Volume 7, The Biennial Report on Freshwater Resources, Island Press, Washington, D.C., 2011.

Grafton, R. Q., Libecap, G., McGlennon, S., Landry, C., and O'Brien, B.: An integrated assessment of water markets: a crosscountry comparison, Rev. Environ. Econ. Policy, 5, 219-239, 2011.

Harou, J. J., Pulido-Velazquez, M., Rosenberg, D. E., MedellínAzuara, J., Lund, J. R., and Howitt, R. E.: Hydro-economic models: Concepts, design, applications, and future prospects, J. Hydrol., 375, 627-643, doi:10.1016/j.jhydrol.2009.06.037, 2009.

Hodgson, S.: Modern water rights: Theory and practice, Food and Agriculture Organization of the United Nations, Rome, 2006.

Howe, C. W., Schurmeier, D. R., and Shaw, W. D.: Innovative Approaches to Water Allocation: The Potential for Water Markets, Water Resour. Res., 22, 439-445, doi:10.1029/WR022i004p00439, 1986.

Jakeman, A. J. and Letcher, R. A.: Integrated assessment and modelling: features, principles and examples for catchment management, Environ. Modell. Softw., 18, 491-501, doi:10.1016/S13648152(03)00024-0, 2003.

Katz, D.: Water markets and environmental flows in theory and in practice, Ecol. Appl., 12, 1247-1260, 2011.

Klaar, M. J., Dunbar, M. J., Warren, M., and Soley, R.: Developing hydroecological models to inform environmental flow standards: a case study from England, Wiley Interdisciplinary Reviews: Water, 1, 207-217, doi:10.1002/wat2.1012, 2014.

Libecap, G., Grafton, R. Q., Landry, C., O’Brien, R. J., and Edwards, E. C.: Water Scarcity and Water Markets: A Comparison of Institutions and Practices in the Murray-Darling Basin of Australia and the Western US, ICER Working Paper No. 28/2010, 2010.

Loucks, D. P., Stedinger, J. R., and Haith, D. A.: Water resources systems planning and analysis, Prentice-Hal, Englewood Cliffs, NJ, 1981.

Loucks, D. P., Van Beek, E., Stedinger, J. R., Dijkman, J. P., and Villars, M. T.: Water resources systems planning and management: an introduction to methods, models and applications, UNESCO, Paris, 2005. 
NERA: The Benefits of Water Framework Directive Programmes of Measures in England and Wales, A Final Report to DEFRA re CRP Project 4b/c, London, UK, 2007.

Poff, N. L., Allan, J. D., Bain, M. B., Karr, J. R., Prestegaard, K. L., Richter, B. D., Sparks, R. E., and Stromberg, J. C.: The Natural Flow Regime, BioScience, 47, 769-784, doi:10.2307/1313099, 1997.

Postel, S. L.: Water for Food Production: Will There Be Enough in 2025?, BioScience, 48, 629-637, doi:10.2307/1313422, 1998.

Postel, S. L., Daily, G. C., and Ehrlich, P. R.: Human appropriation of renewable fresh water, Science-AAAS-Weekly Paper Edition, 271, 785-787, 1996.

Richter, B. D., Davis, M. M., Apse, C., and Konrad, C.: A Presumptive standard for environmental flow protection, River Res. Appl., 28, 1312-1321, doi:10.1002/rra.1511, 2012.

Smakhtin, V. U., Revenga, C., and Döll, P.: Taking into account environmental water requirements in global-scale water resources assessments, Comprehensive Assessment Secretariat, Colombo, Sri Lanka, 2004.

Stern, J.: Water Rights and Water Trading in England and Wales, The Foundation for Law, Justice and Society, Oxford, UK, 2013.

Syme, G. J., Nancarrow, B. E., and McCreddin, J. A.: Defining the components of fairness in the allocation of water to environmental and human uses, J. Environ. Manage., 57, 51-70, doi:10.1006/jema.1999.0282, 1999.
Tharme, R. E.: A global perspective on environmental flow assessment: emerging trends in the development and application of environmental flow methodologies for rivers, River Res. Appl., 19, 397-441, doi:10.1002/rra.736, 2003.

Thobanl, M.: Formal Water Markets: Why, When, and How to Introduce Tradable Water Rights, World Bank Res. Observ., 12, 161-179, doi:10.1093/wbro/12.2.161, 1997.

Ward, F., Booker, J., and Michelsen, A.: Integrated Economic, Hydrologic, and Institutional Analysis of Policy Responses to Mitigate Drought Impacts in Rio Grande Basin, J. Water Resour. Pl. Manage., 132, 488-502, doi:10.1061/(ASCE)07339496(2006)132:6(488), 2006.

Wheeler, S., Garrick, D., Loch, A., and Bjornlund, H.: Evaluating water market products to acquire water for the environment in Australia, Land Use Policy, 30, 427-436, doi:10.1016/j.landusepol.2012.04.004, 2013.

Wilkinson, M.: Farmers won't go with flow, in: Sydney Morning Herald, Sydney, 2008.

Young, M.: Towards a Generic Framework for the Abstraction and Utilisation of Water in England and Wales, UCL Environment Institute Report, UCL Environment Institute, London, UK, 2012.

Young, M. and McColl, J.: Defining Tradable Water Entitlements and Allocations: A Robust System, Can. Water Resour. J., 30, 65-72, doi:10.4296/cwrj300165, 2005. 